\title{
The Responsive Case Study: Action research and action learning in short courses
}

Dr Merrelyn Bates

School of Criminology and Criminal Justice

Mt Gravatt Campus

Griffith University 4111

Queensland

Australia

M.Bates@griffith.edu.au

Merrelyn is a senior lecturer in the School of Criminology and Criminal Justice at Griffith University in Australia. 


\begin{abstract}
This paper describes an adaptation of action research that can be used specifically for the purposes of reviewing educational courses where the participants move out of the research process after one cycle. The author found a limit to the intentional use of action research in her study of a tertiary course that was being offered within the action learning framework of work placements. The term responsive case study was coined to describe the process of planning, acting, observing, reflecting and formulating new plans but in a context where the researcher is completing this process for implementation with the next group of participating students. In addition to being integral to the current implementation of the course, feedback from reflective journals as well as comments and reflections from participating stakeholders become essential for planning the next iteration.
\end{abstract}




\section{The Responsive Case Study: Action research and action learning in short courses}

\section{Introduction}

When an educational practitioner, committed to the notion of an emancipatory curriculum attempts to research her own practice as a curriculum designer, convenor and lead teacher in a university course, the first impulse is to turn to action research as the most appropriate methodology. It offers a disciplined approach to data gathering, analysing, theorising, reporting, planning and then engaging in further action; it is built around a set of assumptions and beliefs that are corroborated by empirical data about how students learn through their own action.

Research into the practices of education has been shown to be most effective when teachers research their own practice. The key to the effectiveness of action research is that new contextualised conceptions about learning and teaching are immediately ploughed back into further practice, initially as new plans and then as further developed action (Herbert Altrichter, Kemmis, McTaggart, \& ZuberSkerrit, 2002). The knowledge constructions that are created tend to be practical and feasible because they arise concurrently with new procedural insights that can be incorporated into the researcher's own practice as a teacher.

When the value set of a researcher is built around emancipatory goals, the outcome of the research needs to be judged on whether or not it empowers the research subjects. McTaggart (1991) draws attention to the fact that action research is a lot more than simply 'objective' research into human action: action research rejects the idea of treating human participants as the 'subjects' of research and demands that not only should their own conceptualisations about what is going on be taken into account, they should actually be able to intentionally influence the outcomes of the research process as, those whose action is being observed and analysed become actors in the research process. 
Thus, McTaggart argues that the most effective forms of action research are participatory and that participants should play a major role in the construction of meaning, the creation of outcomes and the systemic uses of the findings.

However, this leaves a problem for the researcher who attempts to study the 'action learning' of students (i.e. the 'hidden curriculum' which is inherent in what students actually do in response to the course) when the course under investigation is of limited duration. The students do not participate in the course long enough for the action research cycle to turn more than once, and by the time the question has been posed, the observations have been made, the interpretations arrived at and the planning begun for the next cycle, that particular iteration of the course is over and the students have moved on. In my experience, proposals for change come too late and there is often little opportunity to conduct any honest analysis of how the students are making sense of what is happening to them. Instead, research becomes reduced to course evaluations that consist of either performance based tests, simplistic checklists or short responses to questions posed from a frame of reference other than that of the students at the end of the process.

In response to this, I developed an approach, the responsive case study as a methodology that allowed the participants to contribute what they perceived to be relevant data (generally this includes observations, descriptions of action, reflections and analysis) to assist in the planning of the next offering of the tertiary course. Thus, a new cycle of action, observation, reflection and planning followed and any reports or conceptual findings were generated as a set of ongoing reports or as a summary of the whole endeavour at the conclusion. This would form the base for the next iteration of the course and the cycle would occur again with a new group of participant students.

\section{A specific context}

In 2004 I felt the need to examine my own practice: for the past 13 years I have convened a work placement course for final year undergraduates in a Criminology 
and Criminal Justice degree at Griffith University, Australia. More than 60 students per year were placed in an organisational setting similar to the one in which they were likely to commence work at the conclusion of their degree. These placement institutions included a wide range of different government and nongovernment organisations across the areas of law enforcement, corrections, criminal justice, youth justice and family welfare contexts. Those responsible for the 'teaching' of the course included a range of workplace supervisors and consulting academic facilitators as well as myself, who kept the focus of the course through a number of student centred workshops. Students attended the placement organisation for 100 contact hours over the semester and kept a detailed personal reflective journal recording their learning experiences and their responses to them. This journal was maintained as a confidential document seen only by the course convenor for assessment and research purposes (Bates, 2003). The course assessment also required each student to complete an organisationally instigated work task and the student was given the added responsibility of negotiating the assessment weightings with the organisation's supervisor and a nominated academic staff member. Every student also attended four three-hour compulsory workshop seminars at the University that focussed on the practicum experience, and in the semester prior to the practicum they were also required to attend three two-hour compulsory workshop seminars that focussed on particular skills and cognitive processes regarded as essential for achieving graduate employment. Both sets of seminars were conducted with between 15 and 30 students per group.

From 1994 onwards the course had been subjected to regular qualitative evaluations based on my own observations of student responses and the students' immediate written reflections on their experiences in their journals. In 1994 I instituted a policy of obtaining permission from students to retain a copy of the journal and the right to publish selected excerpts with due protection of each student's identity. This permission was always requested after the journals were completed and no student ever refused. The journals were assessed according to criteria that valued reflexivity and the construction of personal meanings. The students commented on both positive and negative experiences with surprising insight and candour. 
In 1994 I collected comments from all of the stakeholders: students, academics, and workplace supervisors (Bates \& Roebuck, 1995) and 1996 I conducted a collaborative evaluation of the course (Bates, Hardacre, Gant, \& Wilkie, 1997), which investigated many of the fine-grained processes of the placement experience. Both of these studies showed that the course was very well received by all involved: the students spoke primarily of the value of applying theory to practice, the emphasis on independent learning, and the value of experiencing a potential employment situation. They made a number of unsolicited comments about their own personal growth and their own development of personal communication skills. The University academics were all confident that the course was effective and all of the workplace supervisors believed that the benefit for students was multi-layered and had particular benefits for their subsequent choice of a career. All stressed that the course challenged students often to the limit of their capabilities.

In 2002 I decided to commence collecting data more systematically and to formalise my methodology so that these ongoing evaluations could be documented into what Robert Stake refers to as a longitudinal instrumental case study (2000). My general research question became: How do students in a field studies based course of limited duration achieve their own maximal learning when involved across a range of agencies with different philosophical contexts? The research question assumed that the course had been shown to be 'effective', but went further: it asked "how?”; in other words it required a study that accessed process information and personal interpretations as the essential data.

\section{The responsive case study}

The methodology described here provides an opportunity for all stakeholders, including the students, to express their own values and criteria upon which judgements are made and action taken. The relevance of the analysis of the research question and the usefulness of the findings depends upon matching the theoretical conceptualisations of specific issues that arise with the language and 
assumptions of several different audiences. It also depends on the extent to which the final report is able to extend the vision of these audiences so that they become aware, at least to some extent, of the point of view of other stakeholders. In this way, the identification of specific issues, sub-questions and the reporting of the findings becomes an exercise in interpretation, translation and mediation.

The case study methodology focuses on a particular course and how its associated practice is currently assimilated into institutional practice. Unlike many case studies, which are concerned with describing a given state of affairs, a responsive case study attempts to investigate the $\underline{\text { dynamics }}$ as well as the structure of a particular event or set of events. As such, it incorporates the voices and opinions of all of the stakeholders involved: in the original study these were the students, workplace supervisors and academics. The emphasis was, however, on the voices of the students and on their interpretations of the convenor's interventions. Such a case study must also be concerned with ongoing action and with the ways in which action can create its own momentum: consequently the focus of the final report has a strong teleological component. This is in line with the kind of existential approach advocated by Feldman (2007) in which he emphasises the importance of choice on the part of students, teachers and action researchers in the ongoing process-continuum of educational endeavour.

\section{Towards a qualitative paradigm for research into the processes inherent in short courses}

If we can consider what happens in a particular course at the level of fine-grained or 'thick' description of the ongoing action (Geertz, 1973) our analysis of subject action can then proceed in terms of impulse and understanding. This allows generalisations at a higher level where actions and their effects are woven into 'strategies', be they conscious (and propositional) or unconscious, implicit or simply not verbalised (and therefore tacit). It also recognises the political implications of action and its proscription (by rules and sanctions) at the level of policy formulation. Issues and questions arise at all levels of this continuum from 
the fine-grained observation of behaviour through to the construction of encompassing theory. The researcher acknowledges the need to be aware that answers and descriptions which are appropriate for one level do not necessarily apply to another.

This approach to enquiry claims to be data driven rather than theory driven (Dick, 2000). It proceeds from the empirical observation of practice and attempts to describe things, as they happen in ordinary conversational language rather than according to any kind of predetermined theoretical structure. This is not to argue that 'ordinary' language does not contain hidden conceptual structures and implicit points of view, but at least it admits different interpretations and does not claim the rigid privilege of formal theoretical constructs.

Ernst Von Glasserfeld argued that “...we cannot know such a thing as an independent objective world that stands apart from our experience of it. ... We cannot speak of knowledge as somehow corresponding, mirroring or representing that world" (cited in Schwandt, 1994, p. 127). Von Glasserfeld's radical constructivism rejects the idea that "knowledge ought to be a veridical 'representation' of a world as it 'exists' prior to being experienced” (Von Glasserfeld, 1991, p. 16 cited in Schwandt, 1994, p. 127), and argues that knowledge cannot be thought of as a product that exists independent of the knower. It is rather an activity. In this view knowledge becomes an instrumental tool rather than a set of verifiable propositions. Von Glasserfeld argues that to know is "to possess ways and means of acting and thinking that allow one to attain the goals one happens to have chosen” (Schwandt, 1994, p. 127). Schwandt notes that radical constructivism provides the opportunity for "reformulating theories of teaching and learning. ... Learning is redefined as a process of experiencing and developing the knowledge construction process, and teaching becomes less a matter of communicating content (i.e. a transmission model) and more a matter of facilitating a process” (Schwandt, 1994, p. 133).

In using the methods of interpretive anthropology and in the acceptance of the fact that knowledge is a process rather than a product, the researcher will inevitably quote extensively from reflective oral or written accounts of action by the actors 
themselves. This means that the initial 'findings' may sometimes appear to be simply descriptions of practice, but they are much more: they are further interpretations of the interpretive data collected from the stakeholders. It includes first-hand observations, but is offered to support higher-level theoretical formulations that are either explicit or implicit in the action. When a researcher attempts to construct higher-order (i.e. more generic) formulations that apply to a group, the question of validity arises and a new paradigm is required. At that stage, the researcher needs to move towards the social constructionist position described by Mary and Kenneth Gergen (2000) who “...instead of focussing on the matter of individual minds and cognitive processes,...turn their attention outwards towards the world of inter-subjectively shared, social constructions of meaning and knowledge” (Schwandt, 1994, p. 127). This approach sees the world as understandable in terms of what Kenneth Gergen (1985) calls “...historically situated interchanges between people. It relies on the shared interpretations of social artefacts - including language - and shares ground with Hans Georg Gadamer’s “philosophical hermeneutics” (cited in Schwandt, 2000, p. 194).

At the centre of the conceptualisation of 'learning through practice' is the notion of intuition. The idea that there is a kind of inexpressible inner knowledge that directs actions (i.e. inner-tuition) is not new: the word has existed in the language virtually unchanged since the $15^{\text {th }}$ century. Robert Witkin (1974) developed a concept of 'the intelligence of feeling', which he saw as "the reflexive component of the affective life" (p. 21). This re-articulates the old notion of 'subject knowing' that can only be expressed in action and this has become implicit in current views of the nature of 'action-knowledge' by recent theorists such as Fuhrer (2004) who sees identity as driven by action and constrained by what he calls 'action possibilities' that arise out of immediate contexts.

Polanyi (1983) has shown that this kind of knowing exists at a different level to the cause-and-effect propositions of science. What he refers to as 'tacit knowledge' is holistic and cannot be expressed directly in language - in Polanyi's words it is 'untellable'. Donmoyer (2000) argues that any model of experiential learning that assumes that the subject consciously creates "working hypotheses" which exist at the tacit level actually misses the point. The very term 'hypothesis' 
implies some kind of cause-and-effect understanding that is propositional, whereas with intuition it is precisely the fact that the tacit knowledge being alluded to is not propositional that makes it different. He remarks “...the relationship of teachers and students - like the relationship of counsellors or social workers and clients - need not necessarily be similar to the relationship between scientist and subject” (2000, p. 57). He goes on to note that Blumer's (1969) concept of 'joint action' “...refers to the creation, through action of a common set of meanings to describe a situation” (2000, p. 57) and infers that such meaning can be shared at a tacit level as each participant in an interaction imaginatively “"take on the role' of the other..." (2000, p. 57). It is this level of 'shared experience' that the research methodology advocated here relies upon: it demands that students reflect upon what has happened to them and then share their common meaning with the researcher. A responsive case study methodology also acknowledges that often learning is 'reflexive' and often proceeds to action without any great degree of conceptualisation at all: it is only when there is a need to share such knowledge with others that 'conceptualisation' becomes necessary and verbalisation is required. It is at this point that propositional knowledge is constructed from pre-existent tacit knowledge and what is 'known' becomes 'theoretical'.

\section{Case study as a methodology}

This research uses an interpretive-constructivist paradigm, which takes a utilitarian view of theory. Schwandt claims that "Interpretive accounts (efforts to make clear what seems to be confused, unclear) are to be judged on the pragmatic grounds of whether they are useful, fitting, generative of further enquiry...” (Schwandt, 1994, p. 130). Because the research involves the construction, elaboration and reconstruction of 'issues', its findings are best developed as a linear narrative. Thus, the reporting style involves the researcher in investigating her own changing and developing constructions while allowing the evolving constructions and interpretations of other stakeholders to emerge as well. 
The need to focus upon relationships and contested expectations implicit in the social action that constitutes the course reflects the notion of case study focussing on 'issues' rather than more abstracted research 'topics' (Stake, 1995). Stake defines case study as “...the study of the particularity and complexity of a single case, coming to understand its activity within important circumstances” (Stake, 1995, p. xi). And while he acknowledges that a central research question is appropriate, he notes that the work of the researcher inevitably places a strong emphasis on interpretation. The questions may be modified as the researcher begins to understand the case and when new issues appear the design can change. The boundaries of the research are set by the definition of the case itself.

Stake (1995) explains that he chooses to use issues as the conceptual structure “... and issue questions as...primary research questions - in order to force attention to complexity and contextuality” (p. 16). He does this not out of a concern for the failure of systems but because he believes that it is in their difficulties that people and their contexts become transparent:

...Issues draw us toward observing, even teasing out, the problems of the case, the conflictual outpourings, the complex backgrounds of human concern. Issues help us expand upon the moment, help us see the instance in a more historical light, help us recognise the pervasive problems in human interaction. (Stake, 1995, pp. 16-17, emphasis mine)

Stake appears to see 'issues' essentially as 'contested constructions' that present themselves as problems of interpretation that impede appropriate action, thus, 'issues' need to become the central unit of discussion in this kind of research.

\section{Research and the development of practice}

The intention of an instrumental case study is to illuminate and to improve practice. It consequently shares a number of assumptions with the paradigm of action research (see Figure 1) and in the study used as an example here, it follows a similar cyclic development through several iterations of the course (see Figure 2). Each iteration of the course can be considered as a separate case study because 
the stakeholders are different and the data collection focuses on different issues as they emerge.

\section{FIGURE 1 HERE}

In my research example, the original study explored the ways in which a particular course (the case itself) responded to changes that were made in response to client and other demands as it was being implemented. Change was built into the implementation process and the course was not described in ways that prohibited this. The study explored the nature of the connections between the curriculum (i.e. the map) and the actual learning that took place (i.e. the territory). Because of this, the case study involved a separate consideration of more than one iteration of the course. It was therefore possible to investigate the resilience of the course; identifying those features that remained stable and accommodated particular kinds of change and those that could not. Specifically, (refer Figure 2)

i) the central issue explored in the first iteration was the general effectiveness or otherwise of the course and its findings (i.e. the pattern of constructions that emerged) were articulated in the report as "challenges" that the stakeholders claimed were faced by students;

ii) the second iteration considered "the role of the convenor" as the issue and the findings took the form of "principles of procedure" that seemed to underlie the implementation of the course; and

iii) the final iteration considered the transferability of these principles to a different convenor and its findings were a set of propositions that became an integrated model for "action-learning" and its hitherto somewhat ignored partner "action-teaching”.

The final report represented a reflective summary of the whole process. It should be noted that political and administrative changes, arising from circumstances external to the course, also became incorporated into each new cycle, and that an analysis of how the course responded to these, was itself used to construct new interpretations and to allow new patterns to emerge from the data. 
Unlike collaborative action research the stakeholders are not contributors to the design of the research or to its redesign in subsequent cycles. Instead, the stakeholders' voices (and their interpretations) are sought and analysed with a view to the researcher extracting, and when possible, implementing suggestions for change based upon her understanding of the constructions that are in contestation (i.e. what Stake would call the 'issues'). As such, the researcher becomes what Denzin and Lincoln refer to as “...the conduit through which the voices can be heard" (1994, p. 23) and the researcher herself introduces the changes in her other role as convenor.

\section{The responsive case study: a methodological framework}

Stake (2000, p. 437) identifies three types of case study: an intrinsic case study is conducted primarily to provide a better understanding of the particular case itself and tends to be less concerned with implications that are more generic or which extend to cases beyond the one that is being analysed; an instrumental case study is conducted as mainly a means of providing evidence for generalisations that go beyond the case itself and may be applied in other circumstances; a collective case study involves the study of more generic problems, phenomena, or conditions that can be illuminated by the consideration of several different specific cases. While this study is concerned with 'the course' as the case, the course itself consists of the subtle interplay of meanings and feelings generated as it progresses and of the responses made to them.

If we revert to an earlier publication by Stake (1975) in which he was primarily concerned with the evaluation of course effectiveness, we find that he pioneered the use of the adjective 'responsive' to describe what he advocated as an effective form of course evaluation. He advocated the collection of data in the form of constructions created by stakeholders in a particular educational course and their incorporation into verbalisations about what was going on in an interim report. When the course was repeated, or the evaluation entered another cycle, changes suggested by these interpretations were incorporated into new and improved procedures. Thus, the evaluation brought about direct changes as it proceeded. 
This was an early answer to a question raised by McTaggart (1990) “...why do...[an evaluation] study unless all that work has some more or less immediately constructive effect?” (p. 3). But a responsive case study is more than just an evaluation: although value judgements are sought throughout the process, the intention is to attempt to identify significant processes, articulate them in causeand-effect terms and come up with improved practices. This leads to statements about procedure - i.e. procedural knowledge. These statements should in turn lead us towards theoretical formulations that can describe and predict outcomes that are applicable to a number of different kinds of field studies based educational courses. All of this then produces generalisations that can lead to improved practices.

This case study had elements of all three kinds of case study identified by Stake and also had a fourth component: it was longitudinal and 'responsive'. Constructions and interpretations made by the students as they went about their own action-learning in one iteration became important areas of focus in the next. This enabled the student voices to be heard in the theory (or 'holding form'). I therefore coined the term responsive case study to refer to this particular piece of research and any others that take a similar form. It should be noted that the responsive case study methodology developed for this piece of research is not necessarily restricted to research into processes inherent in formal educational courses: it can be easily adapted to other settings. The methodology is not necessarily new but the name is useful because while it is not strictly action research, it retains many features of the value system that underlies emancipatory research and can be used to describe a range of other case studies. The responsive case study is therefore an umbrella term to cover the detailed description and investigations into issues that emerge and involves the exploration of problems affecting particular parts of a course, be they structural elements, individual students, groups of students, the behaviour of institutions, or the professional practice of a particular individual. 


\section{Collecting and analysing the data, and reporting the findings}

It was clear from the beginning that in many ways the responsive case study will inevitably become an exploration of values. As Stake notes "the value of [a]...course will be different for different people for different purposes yet there will often be sufficient agreement [between stakeholders] on possible purposes and criteria to sustain useful discourse about the course's merit and shortcomings” (Stake, 1975, p. 25). This description of how he goes about his task as a responsive evaluator could equally apply to that of a researcher who is conducting a responsive case study.

My 'case' was a course designed to incorporate the notion of the 'reflective practitioner' (Schön, 1983, , 1987) to enable trainee professional practitioners to “...face 'situations of practice' characterised by complexity, uncertainty, instability, uniqueness, and value conflict” (Smith, 1998, p. 190). Not only are these the characteristics of the 'issues' faced by most educational researchers, they are the characteristics of the issues that face students too. Commenting on the difference between thoughtful action and reflective practice (particularly when the reflection is in written form), Smith quotes Schön: “...clearly it is one thing to be able to reflect-in-action and quite another to be able to reflect on our reflection-inaction so as to produce a good verbal description of it; and, it is still another thing to be able to reflect on the resulting description” (1987, p. 31 in Smith, 1994, p. 293).

In order to conceptualise or 'objectify' issues and isolate them, it was desirable that all participants keep a written journal that recorded the meaning extracted from the reality of professional action in the field. This became the basis for each student's own 'action-learning'. Consequently, this study had at least three distinct layers, which in many ways interacted with each other. Firstly, there was my own reflective practice as a qualitative researcher, which was addressed by commenting on the kinds of data I found most illuminating as I approached the research question and developed my own research protocols. Secondly, there was 
the reflective practice of the students in the course as they engaged in real experiences in the workplace and then attempted to make sense of them. Thirdly, there were the reflections on my own practice as convenor. This practice consisted of developing the course, supporting the students and interviewing them at regular intervals so that the nature of the experiences they were encountering could be monitored and adjusted so that important deep learnings could occur and I have found that the term 'action' teaching' best emulates the process. Finally, beyond these layers there were moments of insight reported by different stakeholders at different times as they engaged in the sharing that accompanied their own prior reflections.

The methodology enabled me to objectify the reality of my own teaching and to report upon it and then, as a qualitative researcher, to describe any new procedures which led to improvements. It also enabled me to document this procedural knowledge as 'principles of procedure', and to use these principles as a holding form for what others have called 'action knowledge' and to make them available as part of the study's findings.

Perhaps the following example will show how the data parsed these layers and clarify the interlocking nature of the process, the outcomes and the different levels at which the study functioned. It should also serve to give this document some transparency and evocativeness, which Heikkinen, Huttunen and Syrjälä (2007) claim are principles that relate to the worth and value of the research.

Rochelle, a 24 year old student who was initially placed in a community organisation offering counselling services for adults who had been severely abused as children. I drew upon the reflective comments in her journal as the placement proceeded, on her emails to me which indicated that she was becoming anxious, and on subsequent face-to-face contact and discussion for the primary data. Rochelle's organisational supervisor required her to read a number of client files in order to identify the range of variables that could be used in a developing research project for the placement organisation. In her journal she wrote: 
I feel exhausted...and somewhat depressed...because of the nature of the information that the files contain... I'm sometimes upset by what I read... It makes me feel like I'm unable to help these people.

In a one-to-one discussion with me at the time she articulated her alarm at the fact that files she had been reading had triggered vivid memories and nightmares to do with childhood sexual abuse she, herself, had experienced. My contribution was to respond empathically to the feelings she was expressing, to check whether she believed she could continue in the placement and then to point her towards possible courses of action so that she could choose how to manage her recurring distress. She believed that she had 'dealt with' her original trauma but the work experience meant that she was revisiting it. She felt able to continue with the placement and in her journal she noted:

I have discovered that the issues faced by many...clients are also old wounds for me... I have decided that counselling is another option to help me deal with the difficulties I'm facing when working in such an environment.

Subsequently, I was able to check on her progress and to encourage her to articulate her learnings in propositional terms so she could objectify what had happened as a consequence of her choice. In her final journal entry she noted:

I have learnt that I have personal limitations to the type of work in which I can confidently carry out. For example I have personal issues that can be affected by certain tasks such as reading vast material on child abuse.

Subsequent to this, as I reflected on my own teaching, I wrote the following as part of the discussion in my $\mathrm{PhD}$ thesis:

This provides an insight into the paradoxical nature of 'teaching for autonomy'. At first sight the role of the convenor is that of supporter, collaborator and facilitator in true Rogerian non-directive style. But...the convenor sets up the circumstances that make such conflicts inevitable and not just unfortunate accidents. And such conflicts are welcomed as potential learning experiences...

When a factor emerges that was unknown earlier on, like Rochelle's unfortunate history of abuse, I believe the convenor is ethically bound to ensure that, at the very minimum, no damage is done when the challenge 
proves unusually difficult for the student. This means that the convenor needs to have adequate resources of her own (both skills and time) either to deal with the problem herself or to refer the student to others for appropriate counselling and support. At best, the effective convenor will enable the student to take control of the situation herself, to take appropriate action and see the experience as a piece of deeper learning, all of which Rochelle did.

[Rochelle] reported that the sharing of this problem and accepting the fact of the stress itself rather than its cause, was a major step in helping [her] learn how to cope. Her story demonstrates the importance of the convenor's relationship with the student, and with the supervisor. It also highlights the fact that skills in responding to the expression of feelings and in helping the student to develop strategies of action to deal with inner conflicts are required to manage such situations. Such procedures are neither academically nor theoretically driven. They result more from the application of a particular set of values and an intuitive understanding of potential cause and effect relationships to the selection of action appropriate to a given context. Poor management of sensitive situations like this can have negative effects for all concerned.

(Bates, 2005, pp. 186-187)

The research activity was also about making these procedures generalisable and accessible to others through a variety of media and forms. This included not only the above academic text which has been used to assist new staff into the role of action-teacher, but other interactive forms which used a process of modelling and subsequent dialogue have also emerged. For example, during a subsequent iteration of the course I was able to demonstrate my work in a context where I was able to apply similar strategies intuitively and then discuss them with a newly appointed co-convenor. This n turn enabled the co-convenor herself to articulate the new knowledge she had acquired as 'principles of procedure' that were meaningful to her. The co-convenor verbalised her own learnings as conceptual propositions about process and these were incorporated (with appropriate attribution) into my own 'final' report. But since then, this action-teaching, actionlearning and action research chain had developed a life of its own and continues as a central part of the ongoing course. Different kinds of documentation continue to be generated as propositional by-products and are being used for various purposes and by different audiences.

Finally, the responsive case study was also able to generate a broader theory of action-knowledge, action research, action learning and praxis so that action is able to take its place along side discourse instead of being subject to it. This more 
abstract level of theory that arose from practice was directed primarily towards other theoreticians and constructed as a more traditional academic discussion (Bates, 2005).

\section{The findings of the responsive case study}

The interpretations of the stakeholders in my original study were recorded as verbatim quotations from the original sources. The report on the first iteration was concerned with the specific kinds of challenges students identified as significant in the placement. The second iteration became focussed on the role of the convenor and in constructing the set of 'principles of procedure' that were adopted in implementing the course. The third iteration was concerned with the identification of specific kinds of interventions used by the convenor and expressing these as principles of procedure. The final iteration became concerned with the overall philosophy and the kinds of attitudinal change the students reported. The selection of quotations identified emerging patterns and emerging issues. Thus, the narrative of the final report moves from issue to issue as each becomes identified. Additional narratives are included to set the contexts in which the issues are raised. A general discussion that looks beyond each iteration of the case concluded each account and a number of general conclusions, new theoretical points, comments, recommendations and suggestions for action were made in the final section.

In my own reporting I was interested in how original experiences were perceived and then described in journal entries and in how the interpretations and constructions made by different stakeholders abraded against each other. Because I was concerned with changes in the way the course was implemented over time, probably the 'dance' metaphor best describes my reporting (Janesick, 2000). I described changes in constructions and interpretations and consolidated the data into issues or contested constructions that were in the process of change. In the dance, form is continually emerging and dissolving; parties to the dance are altering their relationship (or their 'positions') as the dance proceeds and the meaning of the whole can only be apprehended if it is understood as continually 
changing and 'more than the sum of its parts'. The patterns that emerged from the findings and recorded in the report were those that I was able to perceive in the data and consisted of a kaleidoscope of patterns I recorded as I saw them. Another researcher may have interpreted the data in different ways and so produce different kinds of formulations, but it was my prior work in qualitative research and my considerable experience as a practitioner that allowed me to extract the patterns I did.

\section{Conclusion}

Perhaps the most interesting potential audiences for any responsive case study are the combined groups of students whose stories have contributed to the narrative account. It is quite likely that reports directed to this audience will stimulate them into further action and spawn initiatives for further follow-up course development or as a springboard for fully fledged action research into their own practice and to specific issues stimulated by the report to be taken up by them. Thus, this methodology can become self-generative in a similar way to the original conceptions of action research proposed by Kurt Lewin. As Hilary Bradbury and Peter Reason point out, real quality in action research directly reflects relational praxis, a plurality of knowing which is achieved through conceptual and theoretical integrity, extending our ways of knowing and methodological appropriateness. Most of all, it reflects a deep concern with emancipatory questions, practical concerns and 'greater self-direction both individually and in community' (Bradbury \& Reason, 2006, p. 348). 
References:

Altrichter, H., Kemmis, S., McTaggart, R., \& Zuber-Skerrit, O. (2002). The concept of action research. The Learning Organisation, 9(3), 125-131.

Altrichter, H., Kemmis, S., McTaggart, R., \& Zuber-Skerrit, O. (1990). Defining, confining or refining action research. In O. Zuber-Skerrit (Ed.), Action Research for Change and Development. Brisbane: Centre for the Advancement of Learning and Teaching (CALT) - Griffith University.

Bates, M. (2003). The assessment of work integrated learning: symptoms of personal change. Journal of Criminal Justice Education, 14(2), 303-326.

Bates, M. (2005). Just Practice? Towards a theory of education that uses the workplace as context. Griffith University, Brisbane.

Bates, M., Hardacre, G., Gant, F., \& Wilkie, B. (1997, July). Academic and Workplace Partnerships: The Agenda and Outcomes for Participants in a University Field Placement Experience. Paper presented at the Australian and New Zealand Criminological Society Conference, Brisbane.

Bates, M., \& Roebuck, R. (1995, February). Purposeful Placement in Justice: An Innovation and Evaluation. Paper presented at the Second National Cross Faculty Practicum Conference, Gold Coast.

Bradbury, H., \& Reason, P. (2006). Conclusion: Broadening the bandwidth of validity: Issues and choice-points for improving the quality of action research. In P. Reason \& H. Bradbury (Eds.), Handbook of Action Research: The Concise Paperback Edition (pp. 343-351). London: Sage Publications Ltd.

Denzin, N. K., \& Lincoln, Y. S. (1994). Introduction: Entering the field of qualitative research. In N. K. Denzin \& Y. S. Lincoln (Eds.), Handbook of Qualitative Research (pp. 1-18). London: Sage Publications.

Dick, B. (2000). Data-driven action research. Retrieved 28/03/03, 2002, from http://www.scu.edu.au/schools/gcm/ar/arp/datadriv.html

Donmoyer, R. (2000). Generalisability and the single-case study. In R. Gomm, M. Hammersley \& P. Foster (Eds.), Case Study Method. London: Sage Publications.

Feldman, A. (2007). Teachers, responsibility and action research. Educational Action Research, 15(2), 239-252.

Fuhrer, U. (2004). Cultivating Minds: Identity as Meaning-Making Practice. London: Routledge.

Geertz, C. (1973). The Interpretation of Cultures: Selected Essays. New York: Basic Books.

Gergen, K. J. (1985). Social constructionist movement in modern psychology. American Psychologist, 40, 266-275.

Gergen, M. M., \& Gergen, K. J. (2000). Qualitative inquiry: Tensions and transformations. In N. K. Denzin \& Y. S. Lincoln (Eds.), Handbook of Qualitative Research (2nd ed., pp. 1025-1046). London: Sage Publications Inc.

Heikkinen, H. L. T., Huttunen, R., \& Syrjälä, L. (2007). Action research as narrative: five principles for validation. Educational Action Research, 15(1), 5-19.

Janesick, V. J. (2000). The choreography of qualitative research design: Minuets, improvisations, and crystallisation. In N. K. Denzin \& Y. S. Lincoln (Eds.), Handbook of Qualitative Research (2nd ed., pp. 379-399). London: Sage Publications Inc.

McTaggart, R. (1991). Principles for participatory action research. Adult Education Quarterly, 41(3), 168-187. 
Schön, D. A. (1983). The Reflective Practitioner: How Professionals Think in Action. Aldershot: Arena.

Schön, D. A. (1987). Educating the Reflective Practitioner. London: Jossey-Bass Publishers.

Schwandt, T. A. (1994). Constructivist, interpretivist approaches to human inquiry. In N. K. Denzin \& Y. S. Lincoln (Eds.), Handbook of Qualitative Research (pp. 118-137). London: Sage Publications.

Schwandt, T. A. (2000). Three epistemological stances for qualitative inquiry: interpretivism, hermeneutics, and social constructionism. In N. K. Denzin \& Y. S. Lincoln (Eds.), Handbook of Qualitative Research (2nd ed., pp. 189213). London: Sage Publications Inc.

Smith, L. M. (1994). Biographical method. In N. K. Denzin \& Y. S. Lincoln (Eds.), Handbook of Qualitative Research (pp. 286-305). Thousand Oaks, Calif: Sage Publications Inc.

Smith, L. M. (1998). Biographical method. In N. K. Denzin \& Y. S. Lincoln (Eds.), Strategies of Qualitative Inquiry (pp. 184-224). Thousand Oaks, Calif: Sage Publications.

Stake, R. E. (1975). Evaluating the Arts in Education: A Responsive Approach. Columbus, Ohio: Charles E. Merrill Publishing Company.

Stake, R. E. (1995). The Art of Case Study Research. London: Sage.

Stake, R. E. (2000). Case studies. In N. K. Denzin \& Y. S. Lincoln (Eds.), Handbook of Qualitative Research (2nd ed., pp. 435-454). London: Sage Publications.

Witkin, R. W. (1974). The Intelligence of Feeling. London: Heinemann Educational Books. 


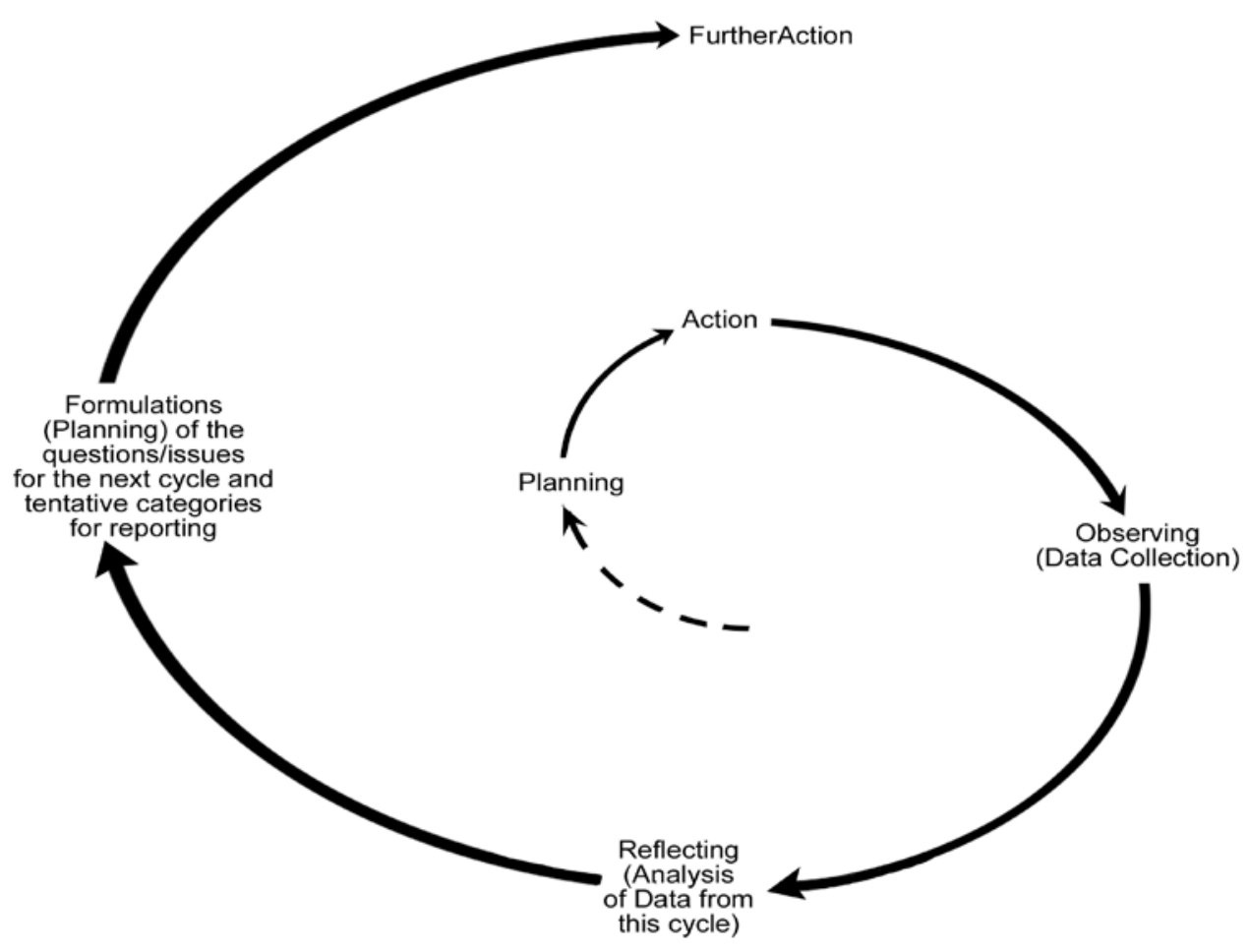

Figure 1: The Action Research Cycle 


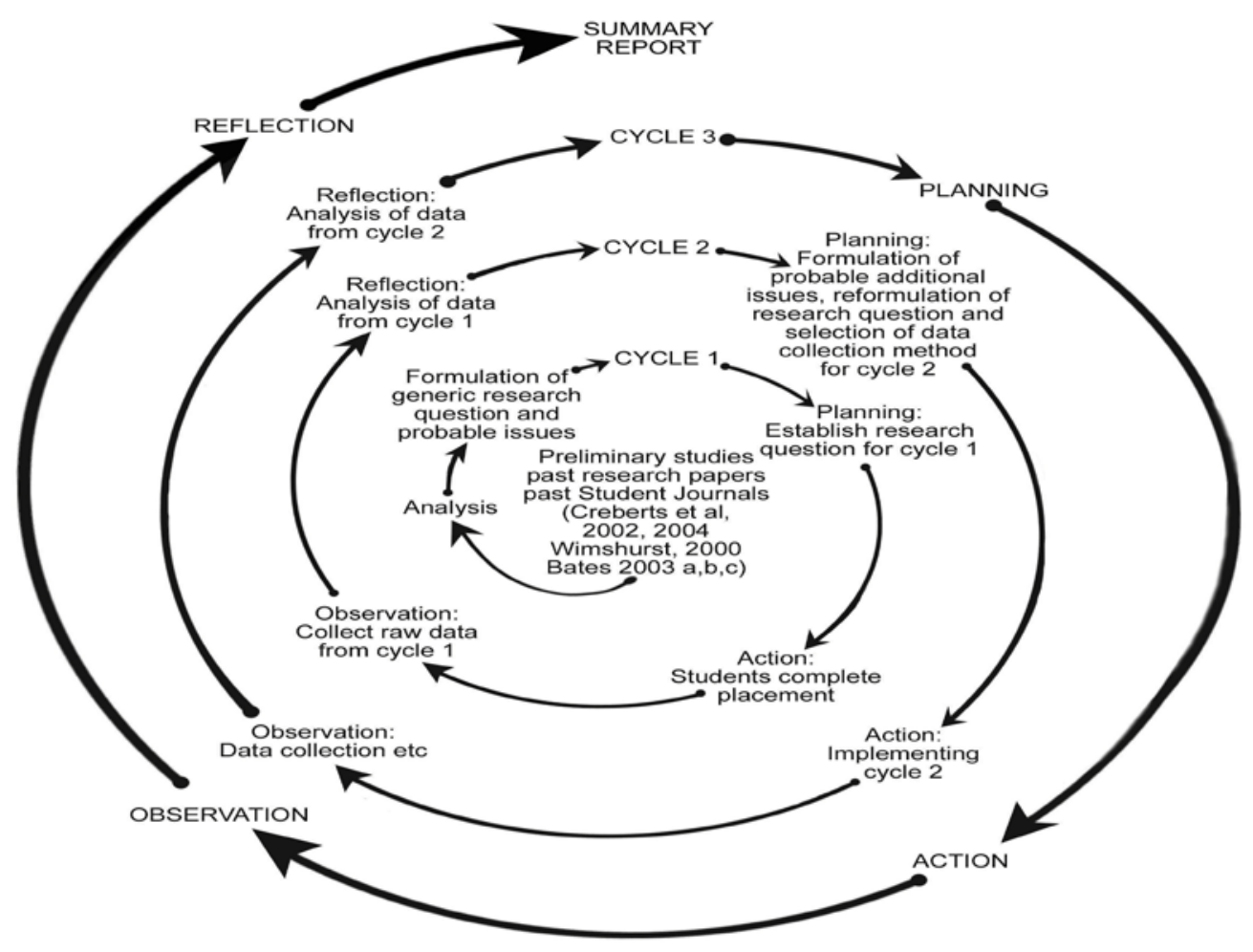

Figure 2: The Responsive Research Process 